\title{
Enhancing electrical contact with a commercial polymer for electrical resistivity tomography on archaeological sites: A case study
}

\author{
Marco D. Vásconez-Maza ${ }^{1}$, Pedro Martínez-Pagán ${ }^{1}$, Hasan Aktarakçii ${ }^{2}$, María C. García-Nieto ${ }^{1}$ and \\ Marcos A. Martínez-Segura ${ }^{1, *}$ \\ 1 Department of Mining and Civil Engineering, Universidad Politécnica de Cartagena; Paseo Alfonso XIII, 52, \\ 30203 Cartagena, Spain; marco.vasconez@edu.upct.es (M.D.V.-M.); p.martinez@upct.es (P.M.-P.); \\ cristinagarcianieto@gmail.com (M.C.G.-N.) \\ 2 Advanced Geosciences, Europe S.L.; Calle del Aire, 85, 28042 Madrid, Spain; hasan@agiusa.com (H.A.) \\ * Correspondence: marcos.martinez@upct.es (M.A.M.-S.); Tel.: +34 968327033
}

\begin{abstract}
This communication reports an improvement of the quality of the electrical data obtained from the application of electrical resistivity tomography method on archaeological studies. The electrical contact between ground and electrode enhances significantly by using carbomer-based gel during the electrical resistivity tomography measurements. Not only does the gel promote the conservation of the building surface under investigation, but it also virtually eliminates the necessity of conventional spike electrodes, which in many archaeological studies are inadequate or not permitted. Results evidenced an enhancement in the quality of the electrical data obtained in the order of thousands of units compared with those without using the carbomer-based gel. The potential and capabilities of this affordable gel make it appropriate to be applied to other geoelectrical studies beyond archaeological investigations. Moreover, it might solve corrosion issues on conventional spike electrodes, and electrical multicore cables usually provoked for added saltwater attempting to improve the electrical contact.
\end{abstract}

Keywords: Electrical resistivity tomography (ERT) method; polymer; carbomer; ground-electrode electrical contact enhancement; archaeology

\section{Introduction}

Archaeological sites contain sensitive and fragile structures that need to be preserved carefully treated. These sites usually have underneath concealed constructions; however, in most of the cases, those constructions have disappeared along the time, or only certain remains are kept in place. In the present, there are available non-destructive exploration techniques, which are referred to as geophysical techniques, to study those invaluable and buried remains from the surface without affecting them. The geophysical assessment gives an overview of the underground allowing identifying subsurface geological formations, services, cavities, ancient concealed settlements, and so forth; according to a noticeable contrast of their measured physical characteristics by means of geophysics. Thus, letting archaeologists detect buried settlement without the need of undertaking harmful operations to those protected structures such as trenching or mechanical drilling. As a result, geophysics has been extensively used in geology, mining, environmental studies, hydrogeology, agriculture, forensics, civil engineering, e.g. [1-5], and where their use in archaeology has not been different due to their proved capabilities. In fact, applied geophysics in archaeology is carried out in the early stages of a subsurface investigation, before any other invasive actions that could damage potential hidden structures, as a useful tool to guide and support all the whole process [6,7]. 
Among all the geophysical techniques, the electrical resistivity tomography (ERT) method is one of the most common technique used in archaeology [8]. Due to the fact that resistivity is a characteristic electrical property of the rock materials and it is related to their lithology, fracturing, saturation, and fluid content. Thus, by obtaining the subsurface distribution of resistivity from measurements on the surface, the structure and composition of subsurface geology, as well as its hydrology can be inferred. The ERT method uses controlled electrical currents which are injected into the ground utilising electrodes to obtain electrical data from the materials underlying into the subsoil. Those electrical data enable to characterise the underneath subsurface of a building. At each measurement, the ERT technique employs four active electrodes, from which two electrodes are used for injecting electrical current into the ground and two electrodes to measure the difference of potential. These active electrodes need to achieve good ground-electrode electrical contact to obtain quality data from the subsurface. At this point, it has to be highlighted that it is common practice to use peak electrodes (traditional spike) which are dug into the ground to both facilitate the injection of electrical current and the decreasing of ground-electrode electrical contact (Fig. 1a) .

However, to nail conventional electrodes into buildings of archaeological interest will be likely to be inadequate or not permitted in many cases (Fig. 1a). That is a relevant matter of concern as that crucial drawback might make the ERT technique unpractical in many situations especially in archaeology. So, to avoid that significant limitation, as an alternative, some researchers have started using flat electrodes and pouring saltwater, adding bentonite or some home-made jell [9] to reduce the ground-electrode electrical contact and increase the electrical flow to the subsurface (Fig. 1b).
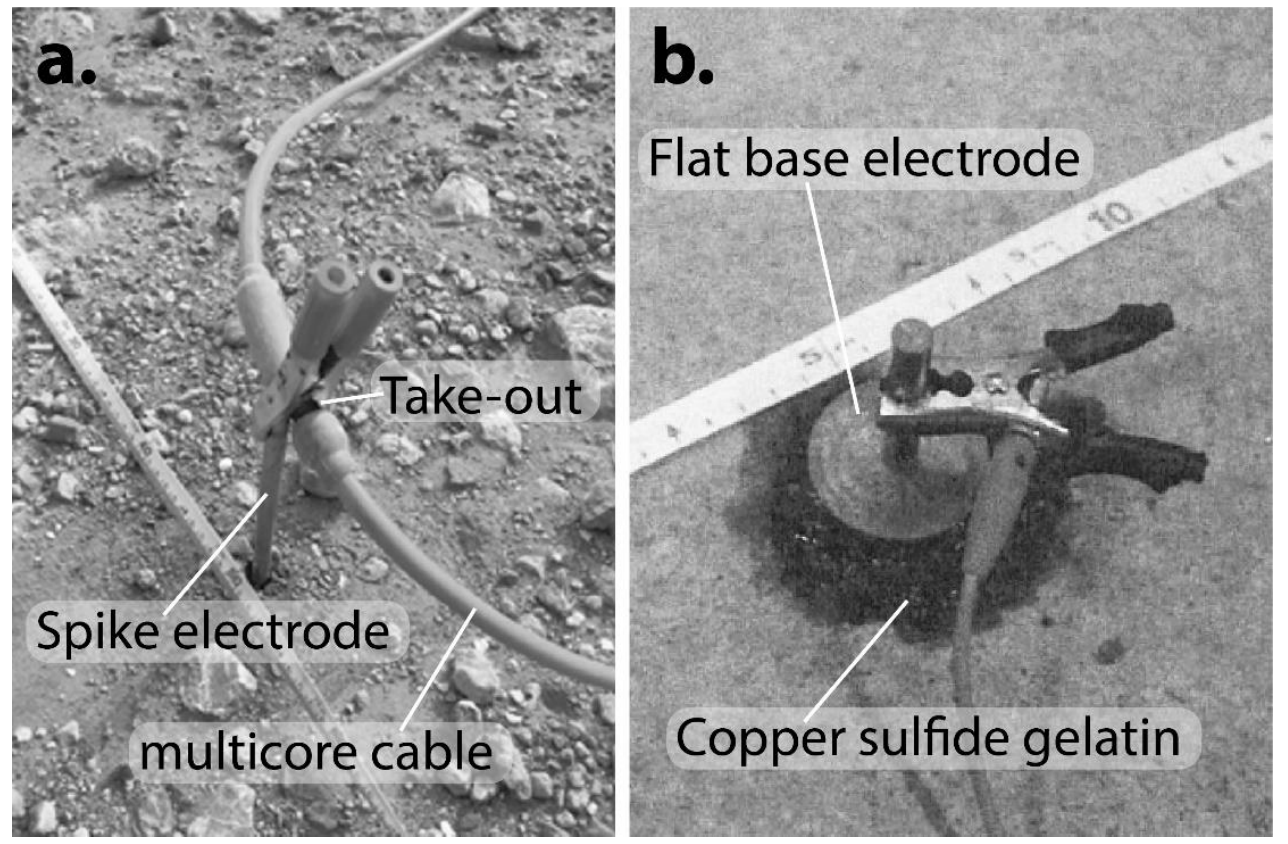

Figure 1. Electrodes used in ERT studies: a) traditional spike electrode, and b) flat base electrode [10].

The aim of this communication is to report the usefulness of a new tested gel to be applied into electrical resistivity tomography (ERT) measurements in protected historical places and quantifying the electrical contact improvement between ground and electrode by means of employing this carbomer-based gel at every take-out of the multicore cable connected to the main resistivity meter.

\section{Study area}

The study was carried out in the Interpretation Centre of Punic Wall (Cartagena, Spain) (Fig. 2), https://puertodeculturas.cartagena.es/ficha muralla punica.asp?idioma=2. It is a museum built around some remarkable Punic wall remains to preserve, study and exhibit their structures to the visitors. The museum houses two main structures, the remains of the Carthaginian 
wall from the Punic Wars, which took place in the third century (B.C.), and a funerary crypt. At its origin the funerary crypt it is believed to have belonged either to the Brotherhood of Saint Joseph or to that of Saint John of Nepomuceno, the most important Brotherhoods that existed at that time. It was built at the end of sixteenth or in the early seventeenth century [11].

Cartagena town is in the southeast of Spain (Fig. 2), which is overwhelmingly plenty of Roman and Carthaginian remains, because of its important role during Punic wars and the posterior Roman period. Most of these archaeological remains are catalogued as a fundamental cultural heritage that must be documented, protected, and their results are offered to the visitors as historical knowledge of the city foundation. Into this framework was conducted the geophysical measurements covered in this communication and their findings.

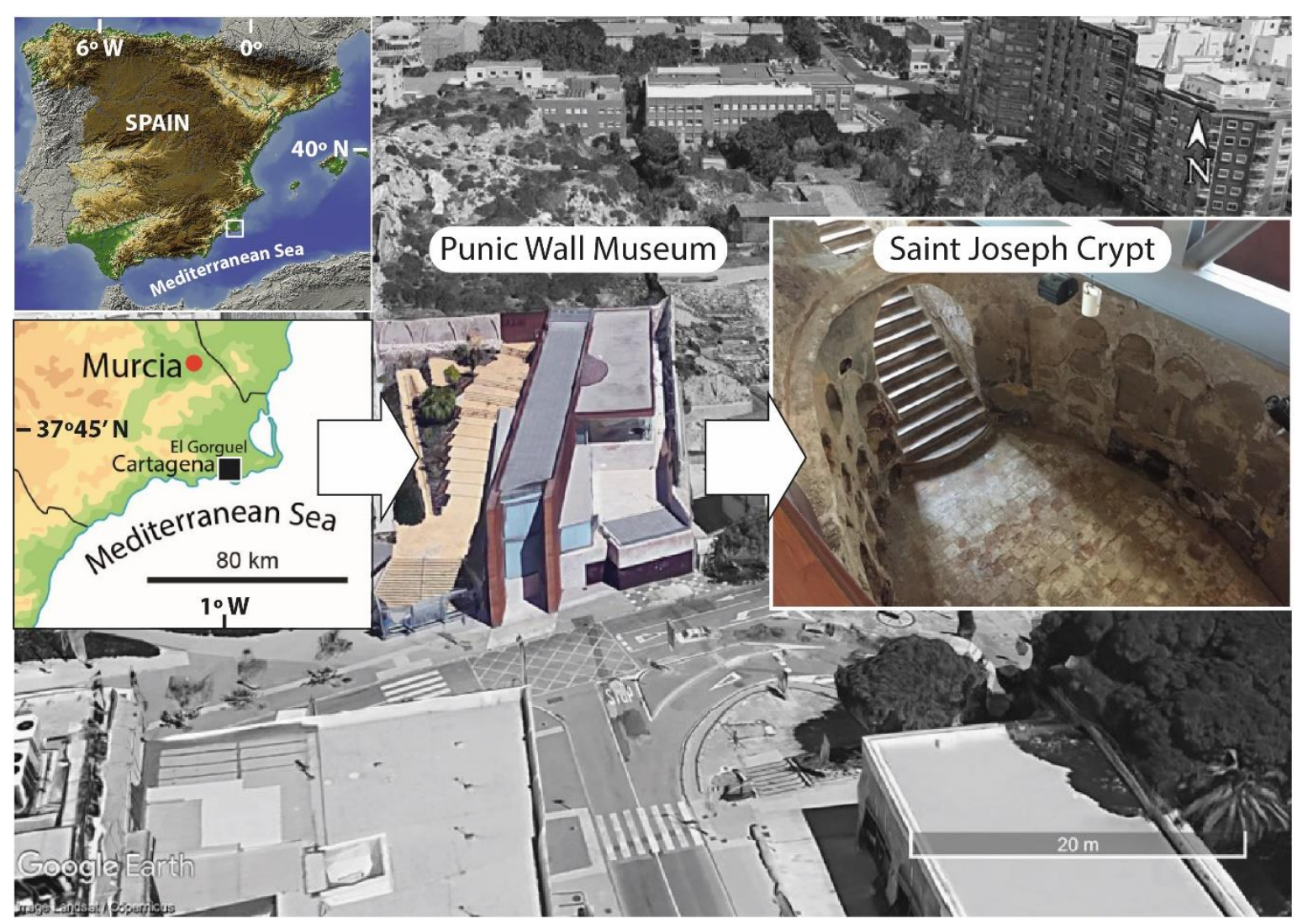

Figure 2. Location and view of the surveyed Saint Joseph crypt in the Punic Wall museum (Cartagena, Spain).

\section{Material and Methods}

\subsection{Electrical resistivity tomography}

The ERT investigation depth depends on the type of array employed for performing the measurements [12]. It was needed to adopt a singular procedure as the crypt of Saint Joseph is a fragile and sensitive archaeological building posing a real challenge for conventional ERT measurements. In this way, through the scientific literature, the employ of Wenner-Schlumberger array $[1-3,13]$ or dipole-dipole array $[4,6,14]$ is commonplace since they provide an excellent signal to noise ratio without compromising the investigation depth. Moreover, in recent indoor investigations, the employ of flat electrodes is being of common use [15] mainly because they do not compromise the floor conditions. Thus, Zouhri et al. [16] demonstrated that flat base electrodes are the most suitable tool for archaeological surveys. Also, Athanasiou et al. [17] were successful in 
employing flat base electrodes to which some cellulose gel was added to improve the electrical contact.

Nowadays ERT method utilizes sophisticated software and hardware that enables us to obtain a considerable amount of electrical data in a very short time. From these measured data, the subsurface structure is inferred at the interpretation stage such as geology, water content, hidden voids, archaeological remains, and so forth [18]. In this work, apparent resistivity data were recorded using a direct current resistivity multi-electrode system (AGI SuperSting R1) [19]. That system is constituted by a high accuracy resistivity meter, a central electrode control unit, four 14-passive electrodes cables, a gas engine generator, cable connectors, and a tablet controller (Fig. 3a). The four passive-electrodes cables allowed set up a total of 56 passive electrodes on the crypt floor following a 3D arrangement with a total length of $27.5 \mathrm{~m}$. The inter-electrode separation was $0.50 \mathrm{~m}$, and the distance between parallel lines was $1 \mathrm{~m}$ apart (Fig. 3b).
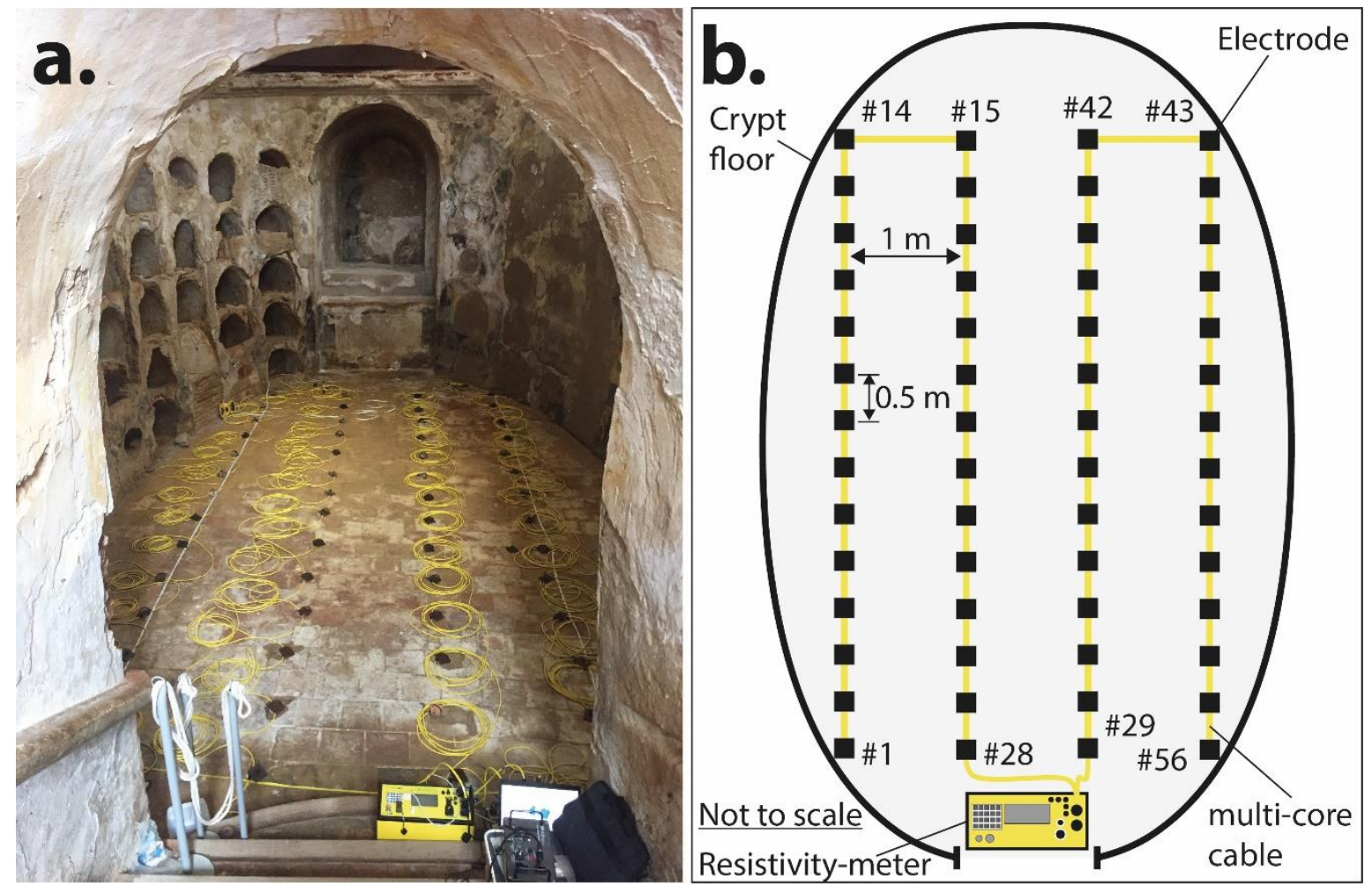

Figure 3. a) 3D ERT layout on the Saint Joseph crypt floor, and b) Sketch of the passive-electrode and cable position.

Then, all the 3D arrangement was connected to the resistivity meter. This controlled-computer central unit provided electrical measurements from the subsurface. Those measurements allowed us to generate an electrical resistivity-based 3D model from the funerary crypt's subsurface. The quality of 3D model resistivity data is crucial to infer from them the crypt subsurface structure. As it was noted before, in this study, the solution adopted to undertake ERT measurements and evaluate their quality was to perform measurements employing two different arrays: dipole-dipole and pole-dipole array, named as measurement \#1 and measurement \#2, respectively.

\subsection{Carbomer-based gel}

As aforementioned, the study area is an important archaeological and protected site where the floor is composed of ancient and relevant tiles; therefore, any drilling or perforating on the museum floor to supply holes to install conventional spike electrodes was not allowed. What is more, the use of clay, which is commonly used with flat base electrodes, was not allowed as it stains the protected 
tiles of the crypt floor. Then, a commercial gel, which is commonly used in laser epilation and/or ultrasound analyses, was tested to evaluate its actual capabilities in improving the ground-electrode electrical contact for ERT archaeological studies. The evaluation of this potential electrical contact improvement through this carbomer-based gel would be important for those archaeological sites under geophysical study in where might be expected sensitive floor made of significant tiles, mosaics, etc. About this commercial gel, its most relevant components are aqua, carbomer, Phenoxyethanol (and) decylene glycol (and) caprly glycol, triethanolamine, and glycerin [6].

Carbomer is a synthetic polymer $\left(\mathrm{C}_{3} \mathrm{H}_{4} \mathrm{O}_{2}\right)_{n}$., alson known as Carbopols, which is a synthetic polymer conformed by acrylic acid chains. These several lateral chains lose protons for acquiring a negative charge. Consequently, these features make it hydrophilic, allowing the absorption of water and augmenting its volume several times [20]. Due to that, it is often used in pharmaceutical applications as both a suspending agent and an emulsifying component in water-based preparations. Moreover, it presents an excellent thermal stability and high viscosity [7].

Previously, the carbomer-based gel has been utilized to increase the electrical contact of those MRI electrodes employed in health studies [21]. Consequently, the primary aim of this study was to test and evaluate the ground-electrode contact using this carbomer-based gel. Provided that its performance is appropriate during ERT tests then it will be recommended for other similar studies. Therefore, to evaluate the ground-electrode resistance contact level, a thick layer of gel was initially added to the passive electrode surface (Fig. 4a), and then some weight was placed on each electrode by means of metallic plates to improve further that contact (Fig. 4b). After that, different electrical configurations were tested, and their results quantified, which are discussed in the next section.
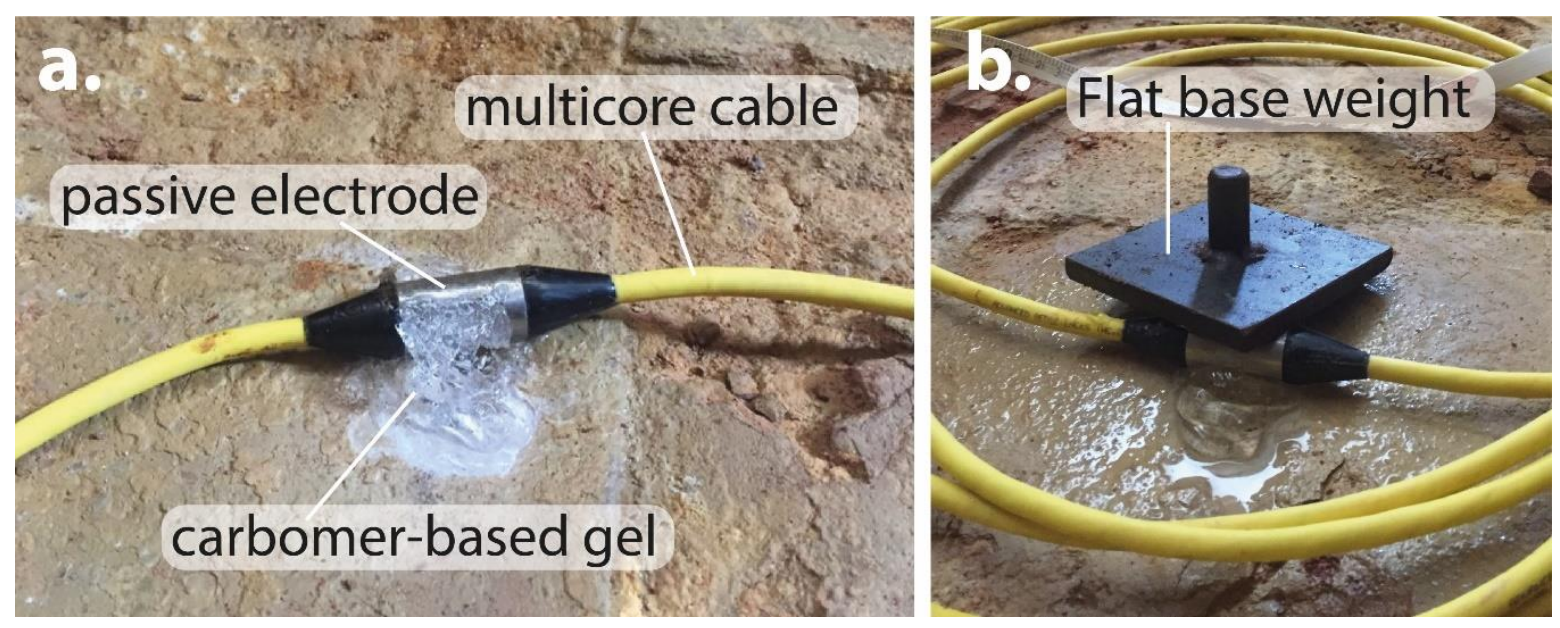

Figure 4. a) Detail about added carbomer-based gel on the passive-electrode surface, and b) flatbase metal weight placed on the passive-electrode.

\section{Results and Discussion}

Before performing the electrical resistivity tomography measurements, it is a must to check the equipment and verify if the electrical ground-electrode contact is appropriate. Otherwise, the data set would include too many anomalous data, or the measurements might not be carried out. An excessive electrical contact resistance characterized by several thousands of ohms leads to inconsistent data making unsuitable the final interpretation or characterization of the subsurface under study. In this way, this electrical contact is the cornerstone of the entire work to obtain quality data.

The first checking measurement consisted of putting the passive electrodes in direct contact with the crypt floor without added gel, whose values are represented by red star symbols in Figure 5a. 
According to the scatter plot, it can be seen that the resistance values obtained during the checking measurements range from about 8000 to $140000 \mathrm{Ohm}$. Thus, this excessive resistance is considered unbearable for ERT quality data. Consequently, it was needed to undertake new rounds of measurement tests but this time with added carbomer-based gel. In Figure 5a are represented the resistance contact values from this dipole-dipole (measurement \#1) and from pole-dipole (measurement \#2) measurements with added carbomer-based gel. It can be seen in Figure 5 a noticeable improvement, in comparison with the checking measurements, of these contact resistance values, which are represented in Figure 5 ranging from below 200 to $1000 \mathrm{Ohm}$. These observed very low contact resistance values, as a consequence of the added carbomer-base gel, which means that most of the electrical current produced from the main unit is injected into the subsurface with minimal electrical losses. Undoubtedly, the more electrical current flow is injected into the subsurface the more accurate will be the information obtained from the subsurface structures.
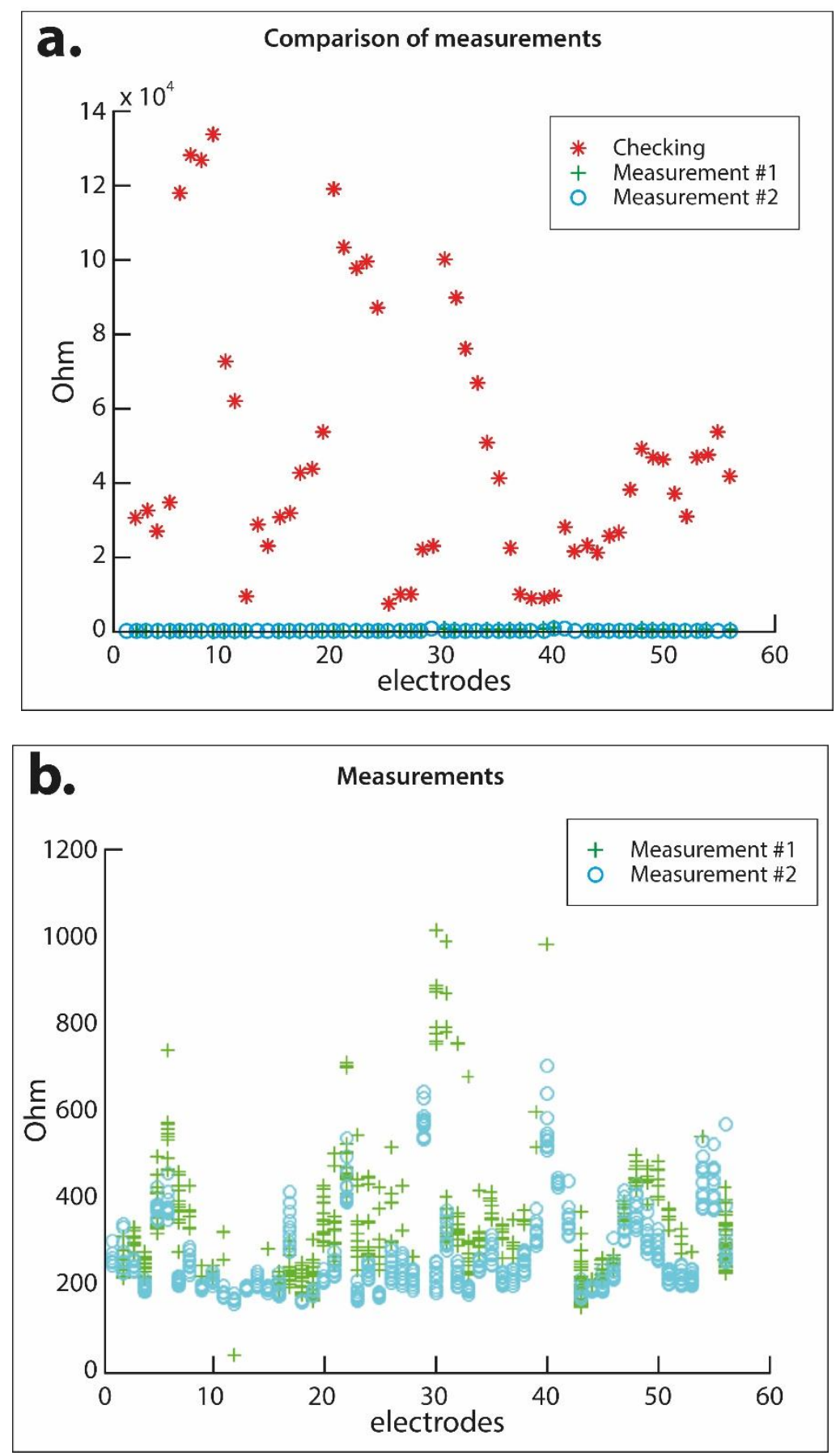
Figure 5. Ground-electrode resistance values at each passive-electrode: a) before using gel (red star symbol), and after using gel during the two test measurements (\#1 and \#2) (represented by blue and cyan symbols), b) only the contact resistance values during the two test measurements (\#1 and \#2) are plotted to properly scale the range of their values.

So, the use of this gel, independently of the chosen array, dipole-dipole, or pole-dipole, enhanced considerably the electrical contact resistance as well as did not stain the tiles of the crypt floor. It is worth noting that adding carbomer-based gel on the passive-electrode surface made unnecessary the employ of flat base electrodes or other non-conventional electrodes. However, it must be said that a little metal weight had to be placed on the passive-electrodes to increase the ground-gel exchange surface. Without any doubt, the use of this commercial carbomer-based gel has turned out to be relevant to those ERT surveys that have to be undertaken indoor as well as on the tile-made floor.

Figure 6a depicts a matching graphic where measured apparent resistivity values versus calculated apparent resistivity values have been plotted. It can be seen the good match between these two sets of data that provides a root mean square (RMS) error of $9.7 \%$ which means that the 3D subsurface inverted resistivity model (Fig. 6b) is considered of high quality and accurate. In this 3D model, the spatial variation of inverted resistivity values is a consequence of the presence of inhomogeneities in the subsurface (moisture content, geology, foundations, etc.), whose interpretation is ongoing and beyond the scope of this manuscript.
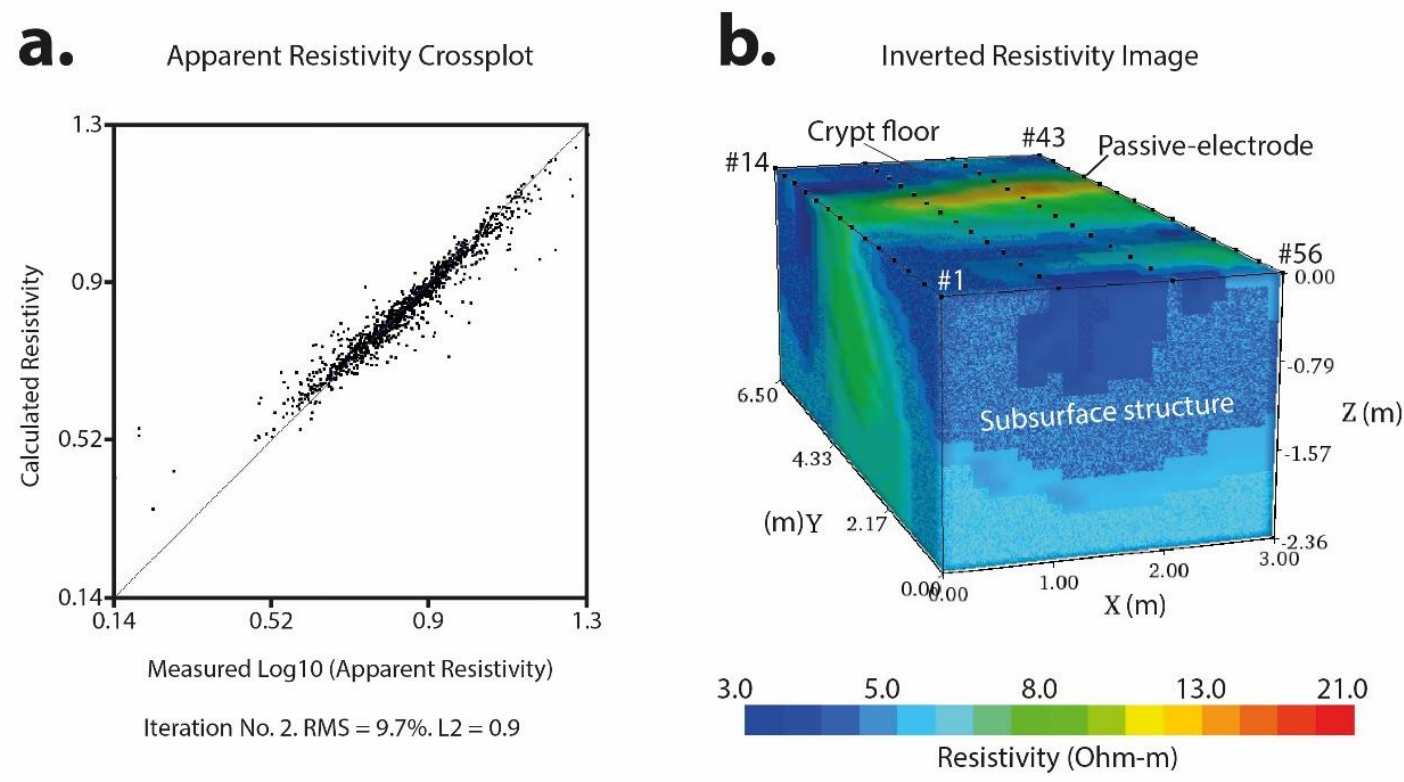

Figure 6. a) Calculated apparent resistivity vs. measured apparent resistivity cross plot, b) Subsurface 3D true resistivity model.

Table 1 summarises the global behaviour of the three test measurements. The minimum value of the checking is $4860 \%$ greater than the minimum value of the measurement $\# 2$ while the maximum value surpasses by $19233 \%$ the maximum value of measurement \#1. The Standard deviation shows the degree of dispersion of the data. It is noticeable that after applying the carbomer-based gel, the range of resistance values is narrowed in comparison with the range obtained during the checking test. Also, the dispersion in the data is significantly reduced after applying the gel so the quality of the measured data will be superior to that without added gel since the data will be more stable.

Table 1. Global behaviour of dataset of contact resistance. 


\begin{tabular}{cccc} 
& No added gel & \multicolumn{2}{c}{ With added Gel } \\
\cline { 2 - 4 } & \multicolumn{3}{c}{ (in Ohm) } \\
\cline { 2 - 4 } & Checking & Measurement $\# \mathbf{1}$ & \#2 \\
\hline min & 7643.3 & 39.4 & 157.3 \\
max & 134249.0 & 1006.1 & 698.0 \\
med & 38147.0 & 289.8 & 229.3 \\
mean & 48880.4 & 316.7 & 264.2 \\
std & 35243.7 & 134.7 & 97.3 \\
\hline
\end{tabular}

${ }^{1}$ min: minimum; max: maximum; med: median; std: standard deviation.

\section{Conclusions}

By applying a carbomer-based gel, the electrical contact enhanced significantly by reducing the contact resistance. This noticeable improvement was observed in the two different arrays tested: dipole-dipole (measurement \#1) and pole-dipole (measurement \#2), which are the common ERT arrays employed in archaeology studies. The excellent electrical contact ensures reliable performance of electrical resistivity tomography providing accurate raw data from which the subsurface structure will be inferred. Also, the physical properties of the carbomer-based gel allowed the placement of the take-out directly on the crypt floor as direct contact. Thus, eliminating the necessity of any flat base electrodes or other non-conventional electrodes. Due to the constituents of this carbomer-based gel, the harmful processes of corrosion observed on traditional electrodes, tweezers, and multicore-cable takeouts due to the added saltwater are eliminated or reduced. Moreover, this carbomer-based gel is affordable, what it is an important point related to widespread use, and since it is a commercial cosmetic product, its access is easy and unlimited. Therefore, it can be concluded that the use of this carbomer-based gel has solved the limitations of the ERT method to be applied in archaeological sites, specifically indoor studies, where is mandatory to improve the contact resistance without affecting the floor conditions.

Author Contributions: Conceptualization, M.A.M.-S., P.M.-P., H.A., and M.D.V.-M.; methodology, M.A.M.-S., P.M.-P. and M.D.V.-M.; software, H.A.; validation, M.A.M.-S., P.M.-P. and H.A.; formal analysis, M.A.M.-S., P.M.-P. and M.D.V.-M.; investigation, M.D.V.-M; resources, M.A.M.-S.; data curation, M.D.V.-M., H.A.; writing - original draft preparation, M.D.V.-M.; writing - review and editing, P.M.-P., M.D.V.-M.; visualisation, M.C.G.-N.; supervision, P.M.-P., M.A.M.-S.; project administration, M.A.M.-S.; funding acquisition, M.A.M.-S. All authors have read and agreed to the published version of the manuscript.

Acknowledgments: Authors acknowledge "Cartagena Puerto de Culturas".

Conflicts of Interest: The authors declare no conflict of interest.

\section{References}

[1] L. Evangelista, F. de Silva, A. d'Onofrio, V. Di Fiore, F. Silvestri, A. Scotto di Santolo, G. Cavuoto, M. Punzo, D. Tarallo, Application of ERT and GPR geophysical testing to the subsoil characterization of cultural heritage sites in Napoli (Italy), Meas. J. Int. Meas. Confed. 104 (2017) 326-335. doi:10.1016/j.measurement.2016.07.042.

[2] M.D. Vásconez-Maza, M.A. Martínez-Segura, M.C. Bueso, Á. Faz, M.C. García-Nieto, M. Gabarrón, J.A. Acosta, Predicting spatial distribution of heavy metals in an abandoned phosphogypsum pond combining geochemistry, electrical resistivity tomography and statistical methods, J. Hazard. Mater. 374 (2019) 392-400. doi:10.1016/j.jhazmat.2019.04.045. 
[3] M.A. Martínez-Segura, M.D. Vásconez-Maza, M.C. García-Nieto, Volumetric characterisation of waste deposits generated during the production of fertiliser derived from phosphoric rock by using LiDAR and electrical resistivity tomography, Sci. Total Environ. 716 (2020) 137076. doi:10.1016/j.scitotenv.2020.137076.

[4] M. Gabarrón, P. Martínez-Pagán, M.A. Martínez-Segura, S. Martínez-Martínez, Á. Faz, J.A. Acosta, Electrical Resistivity Tomography as a Support Tool to Estimate Physicochemical Properties of Mining Tailings Pond, (2020). doi:10.20944/PREPRINTS202001.0377.V1.

[5] T. Martín-Crespo, D. Gómez-Ortiz, S. Martín-Velázquez, P. Martínez-Pagán, C. de IgnacioSan José, J. Lillo, Á. Faz, Abandoned Mine Tailings Affecting Riverbed Sediments in the Cartagena-La Union District, Mediterranean Coastal Area (Spain), Remote Sens. Artic. (2020). doi:10.3390/rs12122042.

[6] K. Simyrdanis, N. Papadopoulos, J. Kim, P. Tsourlos, I. Moffat, Archaeological investigations in the shallow seawater environment with electrical resistivity tomography, Near Surf. Geophys. 13 (2015) 601-611. doi:10.3997/1873-0604.2015045.

[7] S. Grassi, S. Imposa, G. Patti, D. Boso, G. Lombardo, F. Panzera, Geophysical surveys for the dynamic characterization of a cultural heritage building and its subsoil: The S. Michele Arcangelo Church (Acireale, eastern Sicily), J. Cult. Herit. 36 (2019) 72-84. doi:10.1016/j.culher.2018.09.015.

[8] S. Hemeda, Electrical Resistance Tomography (ERT) Subsurface Imaging for Non- destructive Testing and Survey in Historical Buildings Preservation, Aust. J. Basic Appl. Sci. 7 (2013) 344357.

[9] N. Haskins, Book Review - A Field Guide to Geophysics in Archaeology, Archaeol. Prospect. 62 (2010) 61-62. doi:10.1002/arp.

[10] E. Carrara, M.T. Carrozzo, M. Fedi, G. Florio, S. Negri, V. Paoletti, G. Paolillo, T. Quarta, A. Rapolla, N. Roberti, Resistivity and Radar surveys at the Archaeological site of Ercolano, J. Environ. Eng. Geophys. (2001) 123-132. doi:10.4133/JEEG6.3.123.

[11] Fundacion Integra digital, Muralla Púnica - Región de Murcia Digital, Región Murcia Digit. (2020). $\quad$ https://www.regmurcia.com/servlet/s.S1?sit=c,522,m,165\&r=ReP-14117DETALLE_REPORTAJESPADRE (accessed July 16, 2020).

[12] J. Bernard, Short note on the depth of investigation of electrical methods, (2003).

[13] P. Martinez-Pagan, A.F. Cano, E. Aracil, J.M. Arocena, Electrical Resistivity Imaging Revealed the Spatial Properties of Mine Tailing Ponds in the Sierra Minera of Southeast Spain, J. Environ. Eng. Geophys. 14 (2009) 63-76. doi:10.2113/JEEG14.2.63.

[14] S.A.S. Araffa, M.A. Atya, A.M.E. Mohamed, M. Gabala, M.A. Zaher, M.M. Soliman, H.S. Mesbah, U. Massoud, H.M. Shaaban, Subsurface investigation on Quarter 27 of May 15th city, 
Cairo, Egypt using electrical resistivity tomography and shallow seismic refraction techniques, NRIAG J. Astron. Geophys. 3 (2014) 170-183. doi:10.1016/j.nrjag.2014.10.004.

[15] G.N. Tsokas, P.I. Tsourlos, G. Vargemezis, M. Novack, Non-destructive electrical resistivity tomography for indoor investigation: the case of Kapnikarea Church in Athens, Archaeol. Prospect. (2008) 47-61. doi:10.1002/arp.321.

[16] L. Zouhri, P. Lutz, A comparison of peak and plate electrodes in electrical resistivity tomography: Application to the chalky groundwater of the Beauvais aquifer (northern part of the Paris basin, France), Hydrol. Process. 24 (2010) 3040-3052. doi:10.1002/hyp.7719.

[17] E.N. Athanasiou, P.I. Tsourlos, G.N. Vargemezis, C.B. Papazachos, G.N. Tsokas, Nondestructive DC resistivity surveying using flat-base electrodes, Near Surf. Geophys. 5 (2007) 263-272. doi:10.3997/1873-0604.2007008.

[18] M.H. Loke, J.E. Chambers, D.F. Rucker, O. Kuras, P.B. Wilkinson, Recent developments in the direct-current geoelectrical imaging method, J. Appl. Geophys. 95 (2013) 135-156. doi:10.1016/j.jappgeo.2013.02.017.

[19] AGI, SuperSting Wi-Fi, (2020). https://www.agiusa.com/supersting-wifi (accessed July 16, 2020).

[20] L. Ruiz-Rubio, M.L. Alonso, L. Pérez-álvarez, R.M. Alonso, J.L. Vilas, V. V. Khutoryanskiy, Formulation of Carbopol $® /$ poly(2-ethyl-2-oxazoline)s mucoadhesive tablets for buccal delivery of hydrocortisone, Polymers (Basel). 10 (2018). doi:10.3390/polym10020175.

[21] P.K. Patro, K.K. Abdul Azeez, K. Veeraswamy, S.V.S. Sarma, M.K. Sen, Sub-basalt sediment imaging - The efficacy of magnetotellurics, J. Appl. Geophys. 121 (2015) 106-115. doi:10.1016/j.jappgeo.2015.07.010. 